\title{
Automatic Heat Dispel System for DINGSON Biscuit Oven using Thermocouple Temperature Sensor
}

\author{
Mustefa Jibril $^{1}$, HemenTesfaye ${ }^{2}$, Tadele Beyene ${ }^{3}$, Tsinukal Moges ${ }^{4}$ \\ ${ }^{1}$ Msc, School of Electrical \& Computer Engineering, Dire Dawa Institute of Technology, Dire Dawa, \\ Ethiopia \\ ${ }^{2 \& 3}$ Msc, School of Chemical Engineering, Dire Dawa Institute of Technology, Dire Dawa, Ethiopia \\ ${ }^{4}$ Msc, School of Industrial Engineering, Dire Dawa Institute of Technology, Dire Dawa, Ethiopia \\ mustefa.jibril@ddu.edu.et
}

\begin{abstract}
In this paper, an automatic heat dispel system for DINGSON Biscuit Oven have been designed and simulated using Proteus program successfully. This system uses thermocouple temperature sensor to sense the oven temperature and automatically open and close the dispel system. The temperature in which the dispel open and close can be adjusted any time the operator needs to adjust it.
\end{abstract}

Keywords: Dingson, Oven, Thermocouple, Dispel

\section{Introduction}

Industrial ovens are heated plot used for dozens industrial applications, including drying, curing, or baking components. Industrial ovens can be used for large or small scale applications, in batches or continuously with a conveyor line, and a jumble of temperature ranges, sizes and configurations. Such ovens are used in lots different applications, including chemical processing, food production, and even in the electronics industry, where circuit slab are run through a traveler oven to attach surface mount components. The oven contains multiple zones; which tins be individually controlled for temperature. Generally, there are many heating belt followed by one or more cooling zones. The Biscuit moves through the furnace on a conveyor belt, and is therefore subjected to a controlled time temperature profile. Some of this industrial oven have a heat dispel system manually and automatically. In this paper, an automatic heat dispel system for the manual biscuit oven of the DINGSON Biscuit oven have been designed.

\section{System Design}

The heat dispel door design is shown in Figure 1 below. 


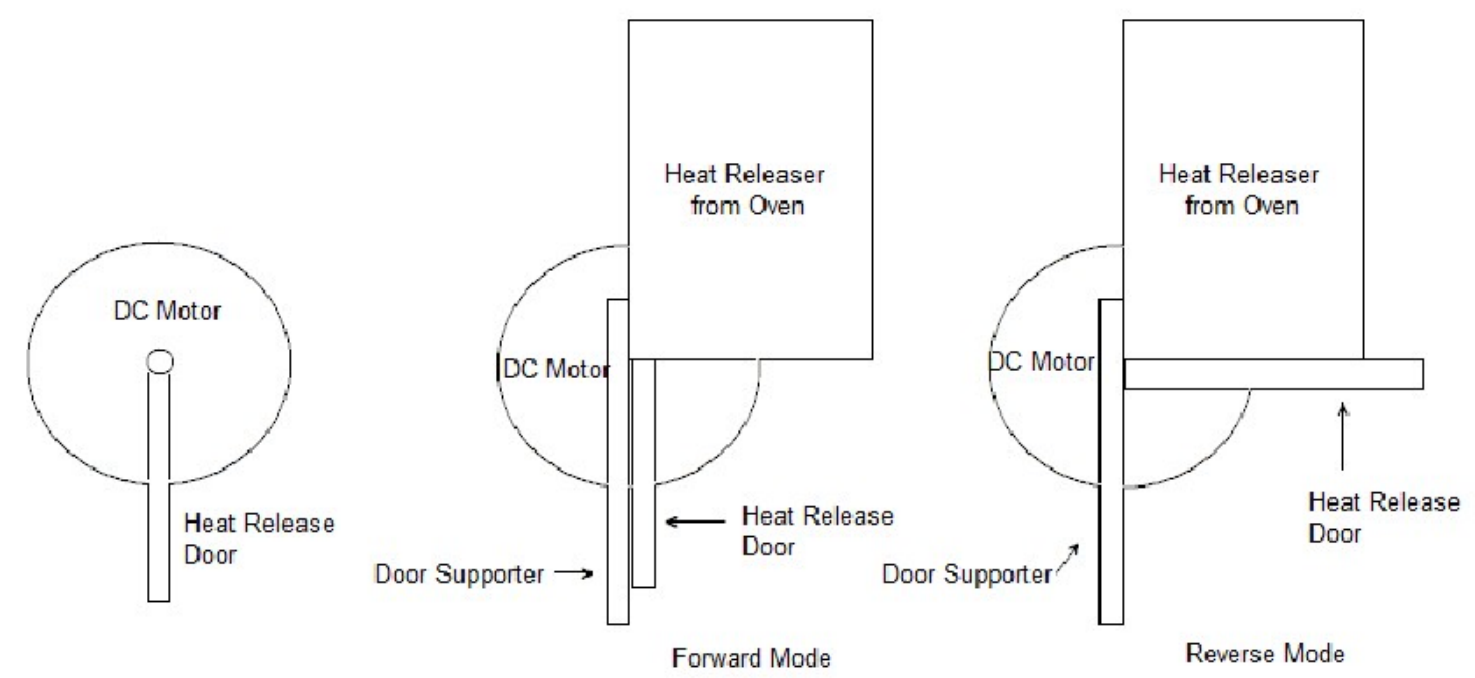

Figure 1 Heat dispel system door design

The system circuit design is shown in Figure 2 below.

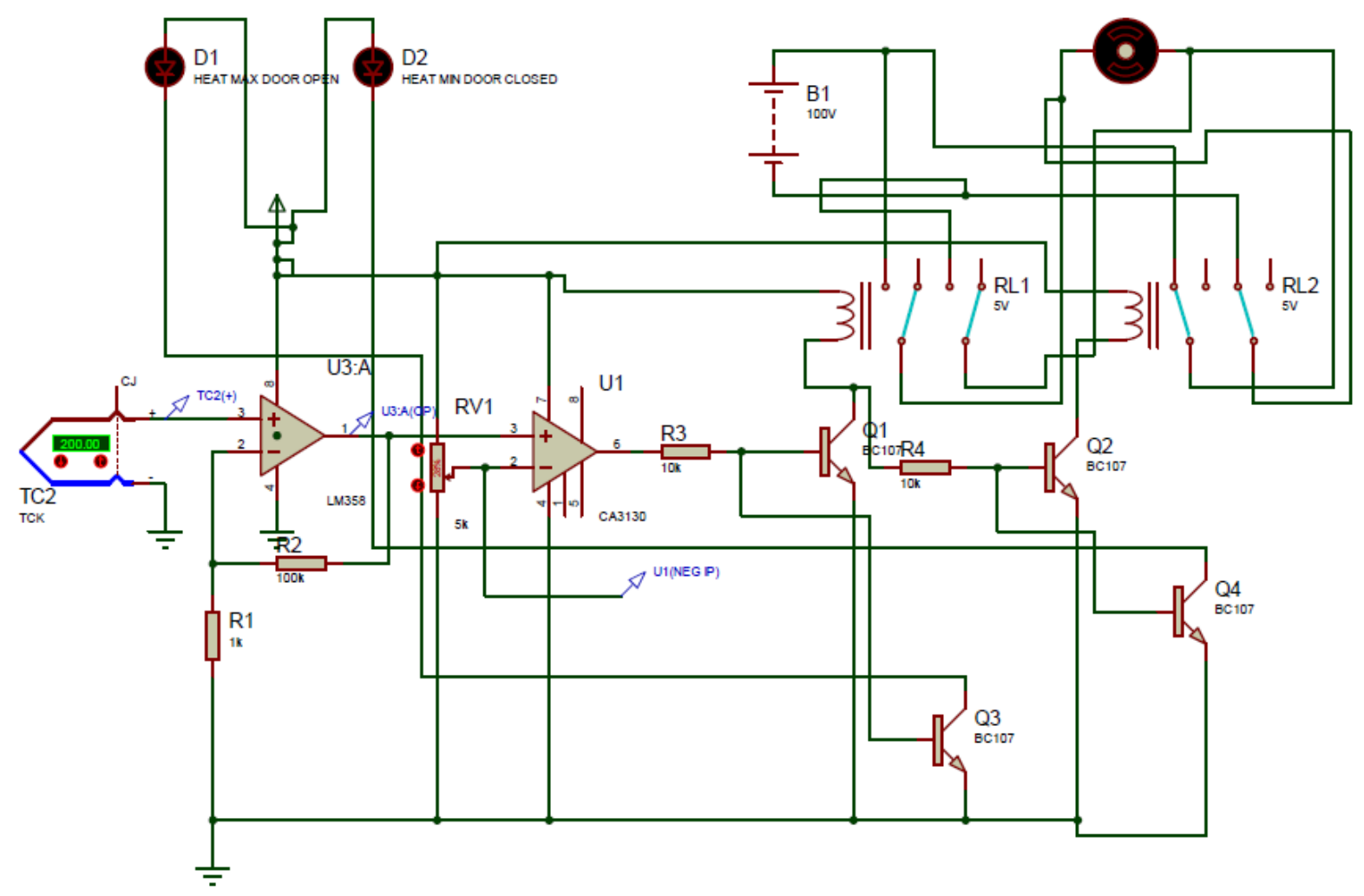

Figure 2 System circuit design

The material needed for this projects are shown in the Table 1 below

Table 1 Material needed 


\begin{tabular}{|l|l|l|l|}
\hline No & Items & Specification & Quantity \\
\hline 1 & Thermocouple & TCK & 1 \\
\hline 2 & Resistor R1 & $1 \mathrm{~K}$ & 1 \\
\hline 3 & Resistor R2 & $100 \mathrm{~K}$ & 1 \\
\hline 4 & Resistor R3, R4 & $10 \mathrm{~K}$ & 2 \\
\hline 5 & Potentiometer & $5 \mathrm{~K}$ & 1 \\
\hline 6 & Transistor & BC 107 & 2 \\
\hline 7 & Relay switch & 2 port, $5 \mathrm{v}$ & 2 \\
\hline 8 & Amplifier & LM358 & 1 \\
\hline 9 & Comparator & CA3130 & 1 \\
\hline 10 & Battery & $5 \mathrm{v}$ & 1 \\
\hline 11 & Voltage source & $100 \mathrm{v}$ DC & 1 \\
\hline 12 & DC Motor & $100 \mathrm{v}$ DC & 1 \\
\hline 13 & Potentiometer (Rotary) & $100 \mathrm{~K}$ & 1 \\
\hline 14 & Jumper Wires & $5 \mathrm{v}$ & 10 \\
\hline 15 & Motor Wire & $110 \mathrm{v} 500 \mathrm{~W}$ & 25 \\
\hline
\end{tabular}

\section{Methodology}

\subsection{Operation of the System}

The thermocouple senses the temperature of the system. Since there is no bias voltage to the thermocouple the output voltage is very small. This output voltage is amplified using the amplifier and given to the comparator. The comparator compares the input voltage and the reference voltage given by the potentiometer and outputted a logic 1 or logic 0 depending on the given voltage. Then the transistors are used like a switch system. Depending on the transistors outputs, the two pole relays will have switched on or off. If the required oven temperature of the oven is 300 degrees or above, the heat dispel system door will open. This means the door of the dispel is controlled by a DC motor rotating in open direction and the reverse will happen if the temperature is $<300$ degrees. The flow chart of the system is shown below.

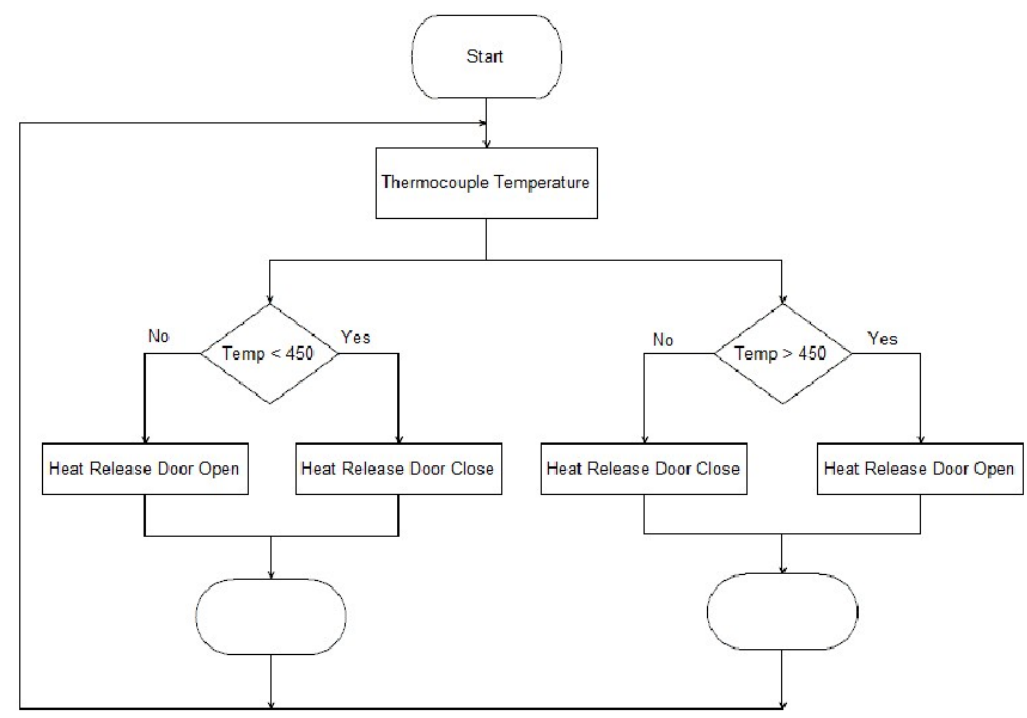


Figure 3 Flowchart of the system

\section{Results and Discussions}

\subsection{Overview}

The proteus simulation model of the system is shown below. The system is designed to open the dispel door for a temperature of 300 and above degree centigrade and to close the heat dispel door for a temperature less than 300 degrees centigrade. This temperature range can be adjusted via the potentiometer attached to the comparator.

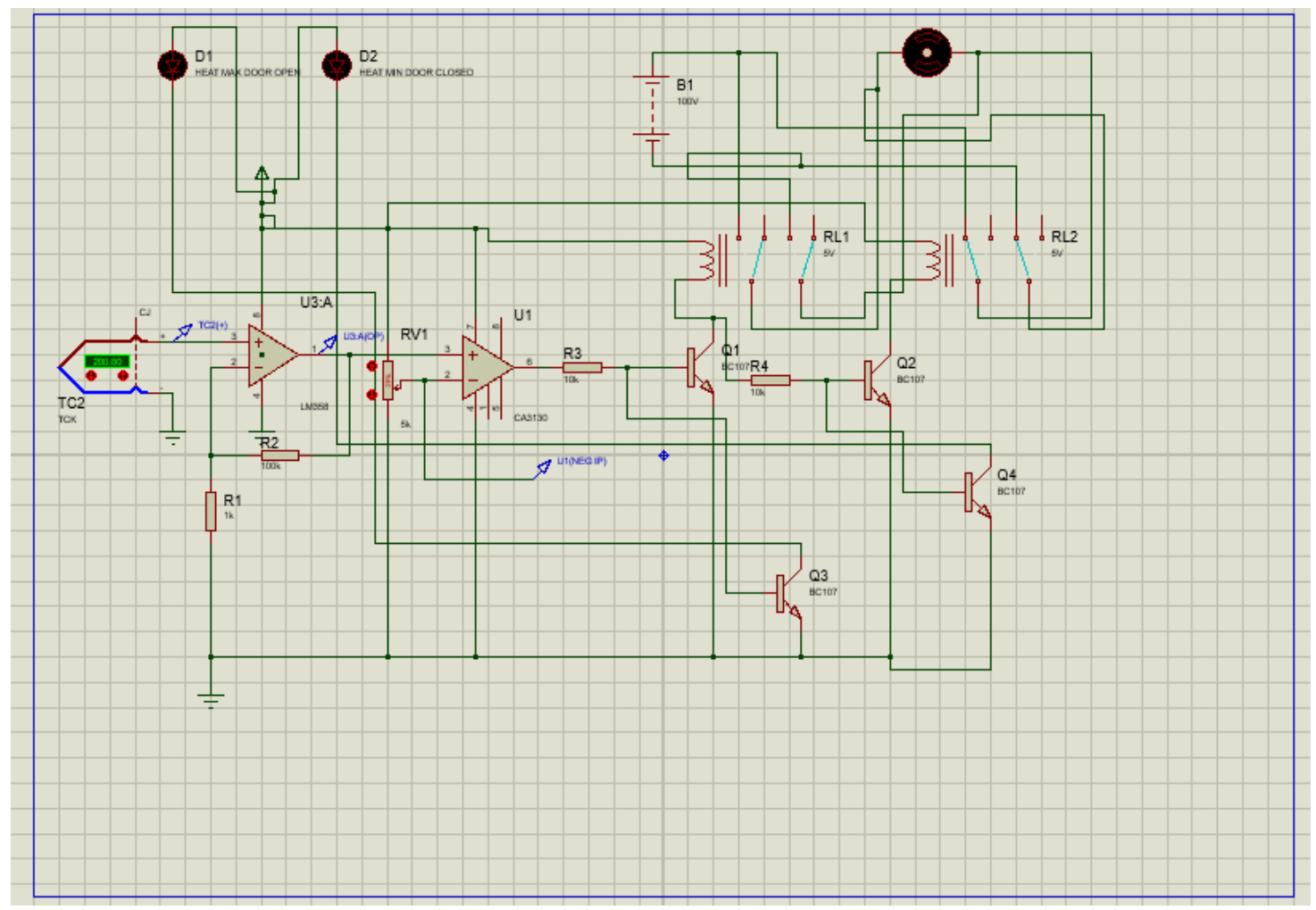

Figure 4 Proteus model

\subsection{Simulation of the Automatic Heat Dispel System for a 200 Degree Centigrade Baking Oven Temperature}

The TCK thermocouple voltage adjustment and the simulation result are shown in Figure 5 and 6 respectively. 


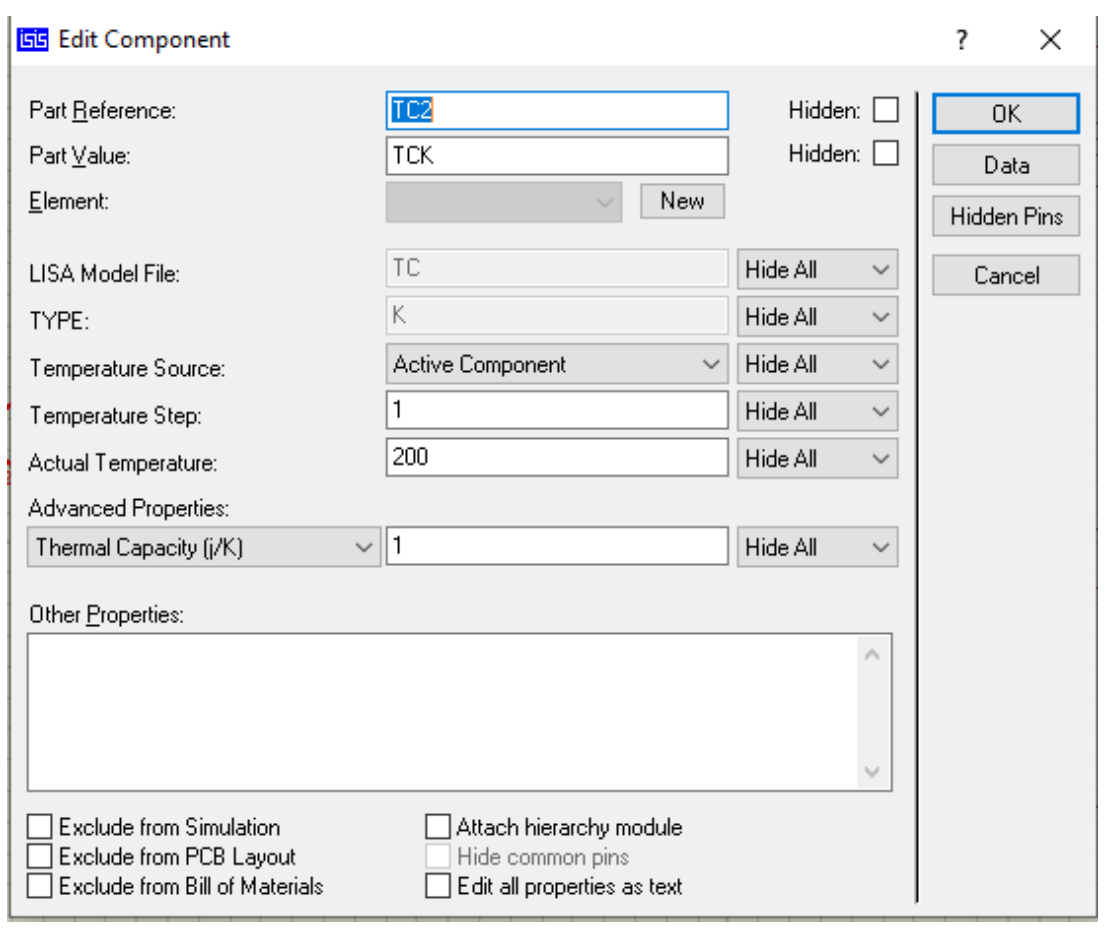

Figure 5 TCK thermocouple adjustment

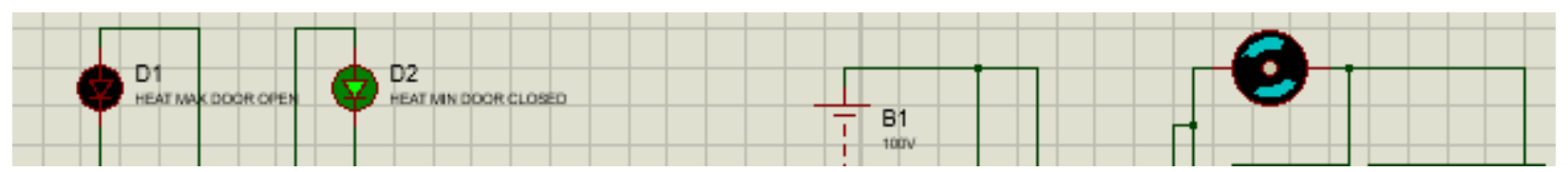

Figure 6 Simulation result

The simulation result shows that the motor is rotating in door close direction and the indicator for heat dispel door closed Green led is on.

\subsection{Simulation of the Automatic Heat Dispel System for a 400 Degree Centigrade Baking Oven Temperature}

The TCK thermocouple voltage adjustment and the simulation result are shown in Figure 7 and 8 respectively. 


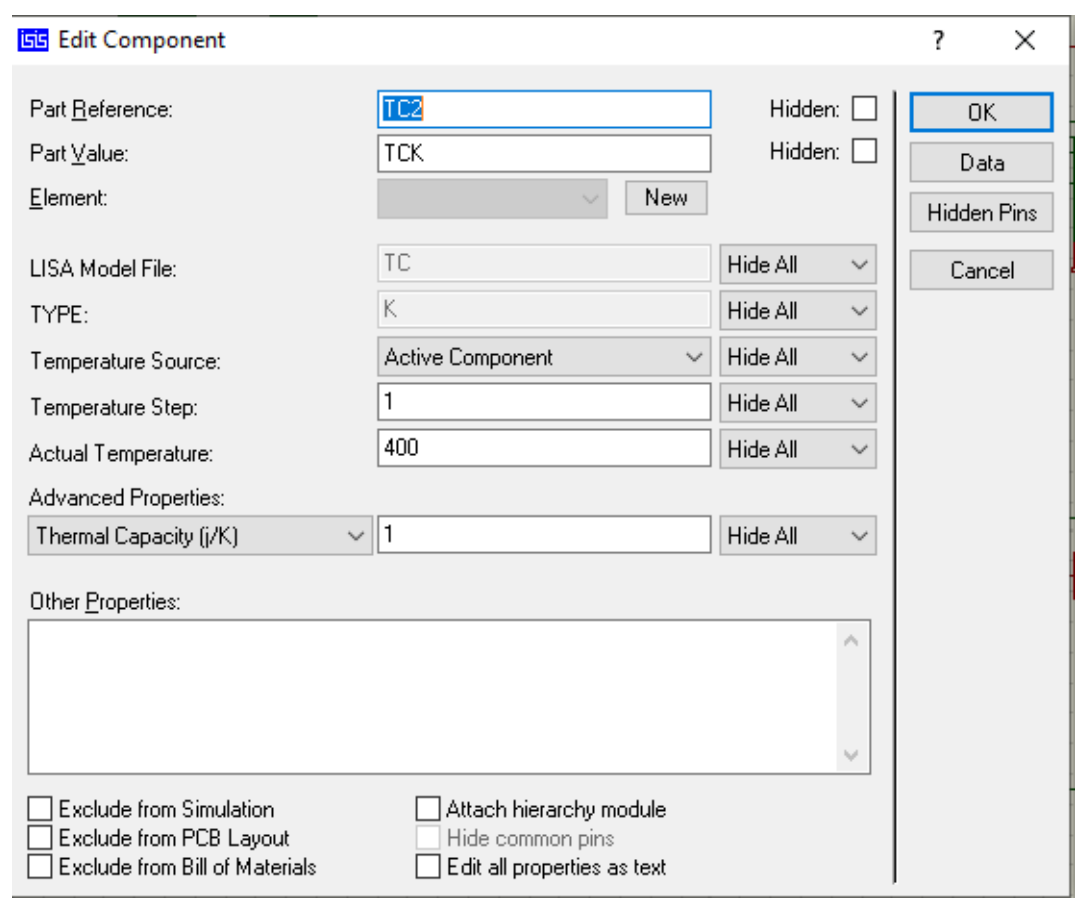

Figure 7 TCK thermocouple adjustment

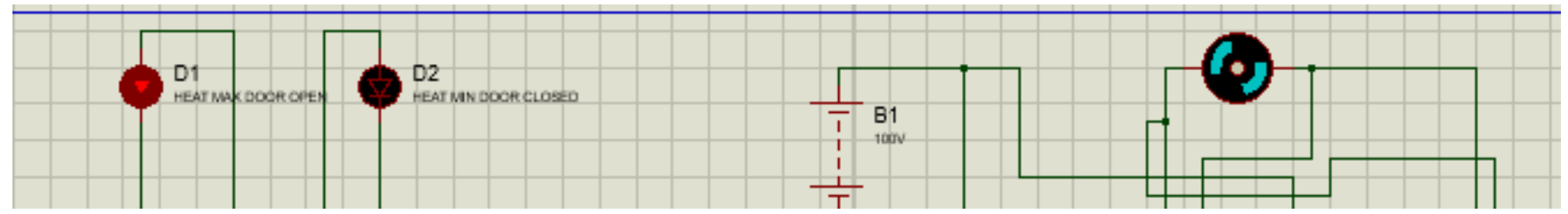

Figure 8 Simulation result

The simulation result shows that the motor is rotating in door open direction and the indicator for heat dispel door open red led is on.

\section{Conclusion}

In this paper, designing and controlling of a DINGSON biscuit oven have been done with the help of Protues software successfully. Thermocouple sensor has been used to sense the temperature of the oven in order to release extra heat from the oven depending on the temperature adjusted by the operator. The temperature range can be adjusted at the desired level for the effect of surrounding temperature. The simulation result shows that the system is effective for the given set point temperature.

\section{Reference}

[1]. "Thermocouple Temperature Sensors" Temperatures.com, Retrieved 2020-08-27.

[2]. Ramseden Ed “Temperature Measurement" Sensors. Retrieved 2020-08-26.

[3]. "LM111/LM211/LM311 Datasheet" Texas Instruments, Retrieved 2020-08-25. 
[4]. Sujith John et al. "PLC Based Induction Motor Starting and Protection" International Journal of Engineering Research and General Science, Vol. 3, Issue 2, 2015.

[5].Pyromation, Inc. "Thermocouple Theory" 2009. 